\title{
A Narrative Review of Diabetes Intervention Studies to Explore Diabetes Care Opportunities for Pharmacists
}

\author{
Shamala Ayadurai, ${ }^{1}$ H. Laetitia Hattingh, ${ }^{1}$ Lisa B. G. Tee, ${ }^{1}$ and Siti Norlina Md Said ${ }^{2}$ \\ ${ }^{1}$ Curtin University, School of Pharmacy, Kent Road, Bentley, Perth, WA 6102, Australia \\ ${ }^{2}$ Ministry of Health, Hospital Sultanah Aminah, Jalan Persiaran Abu Bakar Sultan, 80100 Johor Bahru, Johor, Malaysia \\ Correspondence should be addressed to Shamala Ayadurai; shamala.ayadurai@postgrad.curtin.edu.au
}

Received 12 January 2016; Accepted 14 April 2016

Academic Editor: Andrea Flex

Copyright (c) 2016 Shamala Ayadurai et al. This is an open access article distributed under the Creative Commons Attribution License, which permits unrestricted use, distribution, and reproduction in any medium, provided the original work is properly cited.

Background. We conducted a review of current diabetes intervention studies in type 2 diabetes and identified opportunities for pharmacists to deliver quality diabetes care. Methods. A search on randomised controlled trials (RCT) on diabetes management by healthcare professionals including pharmacists published between 2010 and 2015 was conducted. Results and Discussion. Diabetes management includes multifactorial intervention which includes seven factors as outlined in diabetes guidelines, namely, glycaemic, cholesterol and blood pressure control, medication, lifestyle, education, and cardiovascular risk factors. Most studies do not provide evidence that the intervention methods used included all seven factors with exception of three RCT which indicated $\mathrm{HbAlc}$ (glycated hemoglobin) reduction range of $0.5 \%$ to $1.8 \%$. The varied HbAlC reduction suggests a lack of standardised and consistent approach to diabetes care. Furthermore, the duration of most studies was from one month to two years; therefore long term outcomes could not be established. Conclusion. Although pharmacists' contribution towards improving clinical outcomes of diabetes patients was well documented, the methods used to deliver structured, consistent evidence-based care were not clearly stipulated. Therefore, approaches to achieving long term continuity of care are uncertain. An intervention strategy that encompass all seven evidence-based factors will be useful.

\section{Introduction}

Diabetes contributed to 1.2 million worldwide deaths in 2012 [1]. In people with diabetes, approximately $50-80 \%$ of mortality is attributed to cardiovascular disease [2]. Diabetes is the leading cause of kidney failure [3] and also contributes to one percent of global blindness [4]. In terms of healthcare burden it was estimated that in 2010 diabetes contributed to 4-7 billion United States Dollar (USD) in health expenditure in Australia, USD 7-15 billion in the United Kingdom (UK), and USD 197-344 billion in the United States of America (USA) [5].

As the incidence of diabetes and health burden continues to rise [3] a new approach in diabetes management is imminent. The overall aim of diabetes care is to improve patients' quality of life, prevent early death and reduce the burden of disease [6]. Nevertheless, diabetes is a complex disease as there is a need to address multiple factors in order to achieve quality diabetes care. Addressing multiple factors is referred to as multifactorial intervention or multifactorial treatment and has been described in previous studies [7-13].

This is a narrative review of multifactorial intervention studies from selective literature and explores potential opportunities for pharmacists to deliver quality diabetes care in patients with type 2 diabetes. Findings from this review are useful in addressing current practice challenges.

Aim of Narrative Review. The aim of this research is to review current diabetes management practices targeted towards improved diabetes control and prevention of diabetes related complications. The objectives are to

(1) critique diabetes studies in terms of diabetes guidelines,

(2) determine intervention methods used by healthcare professionals involved in diabetes care with a particular focus towards diabetes intervention services by pharmacists, 
(3) identify key areas where multifactorial interventions are lacking and explore opportunities for pharmacists in diabetes care.

\section{Method}

Keywords used in database searches were "diabetes", "pharmacist", "intervention" or "tool", and "randomised controlled trial" (RCT). Databases used included the Cochrane Library, PubMed, Medline (Web of Science), ProQuest, Scopus, and Medline Ovid. Searches were limited to articles in the English Language, published between January 2010 and August 2015 and included both type 1 and type 2 diabetes. The findings from the search are presented as a narrative review.

\section{Results and Discussion}

3.1. Multifactorial Diabetes Care. There were several landmark trials that provided significant evidence that led to improved diabetes management outcomes, namely:

(1) The United Kingdom Prospective Diabetes Study (UKPDS) carried out in the UK [14].

(2) The Action in Diabetes and Vascular Disease: Preterax and Diamicron MR Controlled Evaluation (ADVANCE) study carried out in 20 countries throughout Asia, Australia, Europe, and North America [15].

(3) The Veterans Affairs Diabetes Trial (VADT) in the USA [16].

(4) The Diabetes Control and Complications Trial (DCCT) in the USA [17].

(5) The Action to Control Cardiovascular Risk in Diabetes (ACCORD) study carried out in the USA and Canada [18].

Table 1 is a summary of these trials. Findings from the trials provided evidence that three main factors need to be addressed to achieve therapeutic targets and consequently prevent diabetes complications, namely, glycaemic, blood pressure (BP), and cholesterol control.

These factors have been incorporated into clinical practice guidelines (CPGs) on diabetes management from Australia, Europe, the UK, and the USA. In addition, CPGs from these countries recommend management of four other factors in diabetes management. These are medication management, lifestyle, education, and cardiovascular risk management. These seven diabetes factors are summarised in Figure 1 and discussed in the following paragraphs.

(1) Glycaemic Control. Diabetes guidelines recommend a target HbAlc (glycated haemoglobin) of $7 \%$ or less. Glycaemic control should aim to reduce HbAlc by $1 \%$ or more for patients whose HbAlc is more than $7 \%$, as this can lead to significant reduction in microvascular complications, as was shown in the UKPDS trial [14]. The results from the landmark trials highlight several factors that need to be emphasised to prevent hypoglycaemia such as individualised glycaemic targets, educating patients on hypoglycemia awareness, selfmonitoring of blood glucose levels, adjusting therapy, and changing to treatment that causes low risk of hypoglycemia [20-23].

(2) BP Control. Blood pressure less than $150 / 85 \mathrm{mmHg}$ has demonstrated a reduction of microvascular and macrovascular complications [14]. The American Association of Clinical Endocrinologists and American College of Endocrinology CPGs on diabetes strongly suggests a target BP of less than $140 / 80-90 \mathrm{mmHg}$ and recommended an update from the previous target of less than $130 / 80 \mathrm{mmHg}$ [24]. However Australian guidelines recommend a target of $130 / 80 \mathrm{mmHg}$ or lower and 125/75 $\mathrm{mmHg}$ for diabetes patients with proteinuria. Diabetes guidelines from Australia and the USA advise on the need to reduce sodium intake, increase potassium intake, and moderate alcohol consumption $[25,26]$. These guidelines recommend prescribing, unless contraindicated, an Angiotensin Converting Enzyme Inhibitor (ACEI) or Angiotensin Receptor Blocker (ARBs) as the preferred antihypertensive.

(3) Cholesterol Control. Guidelines from Australia, the UK, and USA stress the importance of use of a lipid-regulation medication such as a statin unless contraindicated, to reduce the risk of developing cardiovascular disease (CVD). Although there is increased risk of developing diabetes with statin use [27, 28], several meta-analysis on randomised trials show evidence of increased benefit of statins in terms of reduction in cardiovascular risk $[29,30]$. The current safety advice from the USA Food and Drug Administration [31] and Australian Diabetes Guidelines [25] outlines the benefits of statins in preventing cardiovascular events over the increased glycaemia risks.

(4) Medication Management. Medication management requires that each patient's medicine related needs be addressed to achieve target therapy outcomes. Pharmacists play a main role in medication management that involves identifying, resolving, and preventing medication-related problems [32]. Medication-related problems include inappropriate medication, incorrect or inappropriate dose, medicine interactions, adverse medicine reactions, and unnecessary medicine use [32].

Addressing patients' medication-related problems facilitates achievement of treatment goals, as documented in a study of 2620 patients in the USA seen by pharmacists [33]. In a similar randomised prospective study of 107 Latino patients in the USA, followed up for two years, adherence to medication was the strongest predictor of reaching the target HbAlc [34]. Reducing hypoglycemia episodes has also been associated with increased patient adherence and satisfaction with medication [35]. Several studies suggest that diabetes patients who are adherent in taking their medication reduce overall healthcare burden, even though this could mean an increase in medication costs [36-40].

(5) Lifestyle. Lifestyle factors such as diet intervention, exercise, smoking cessation, moderation of alcohol consumption, 


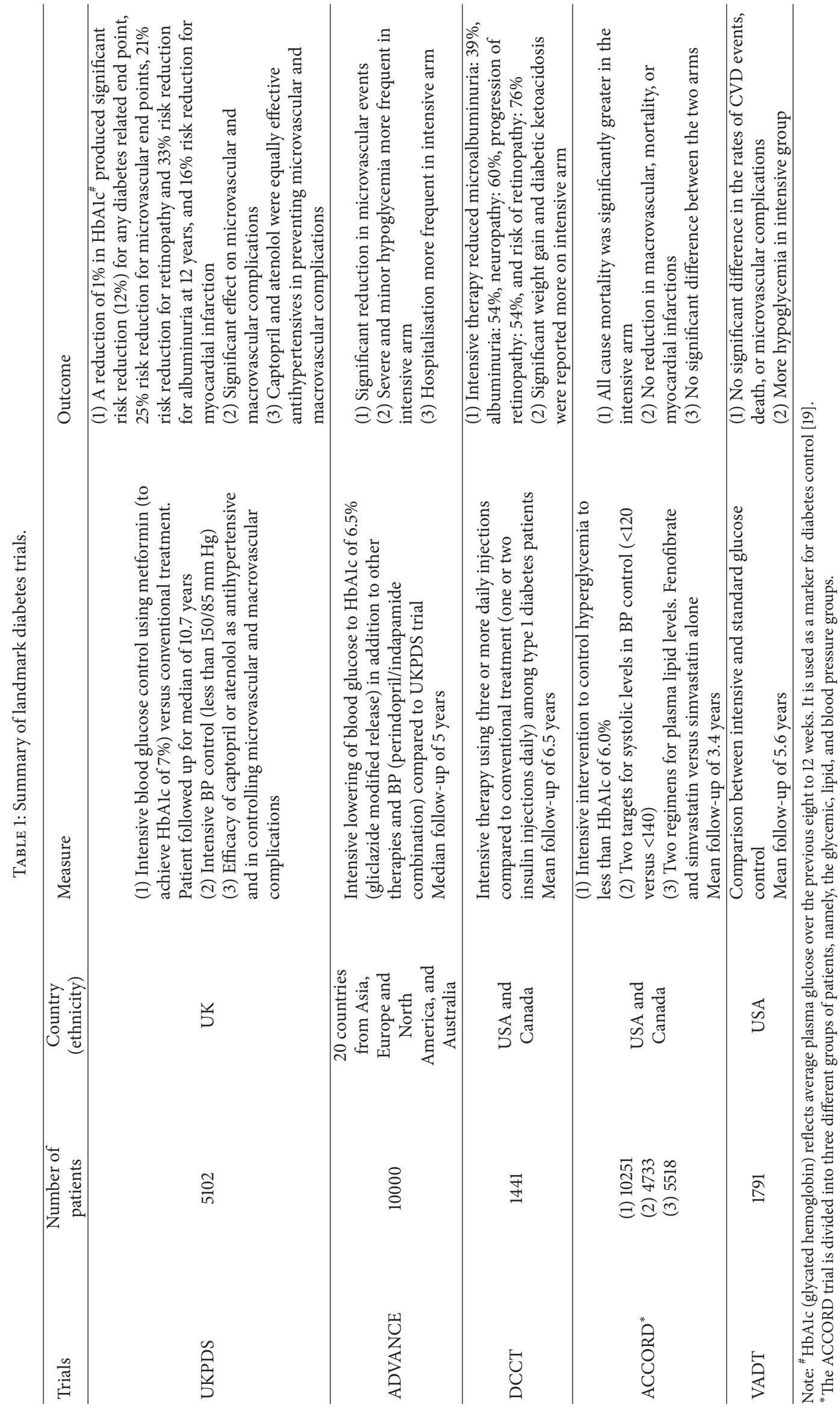




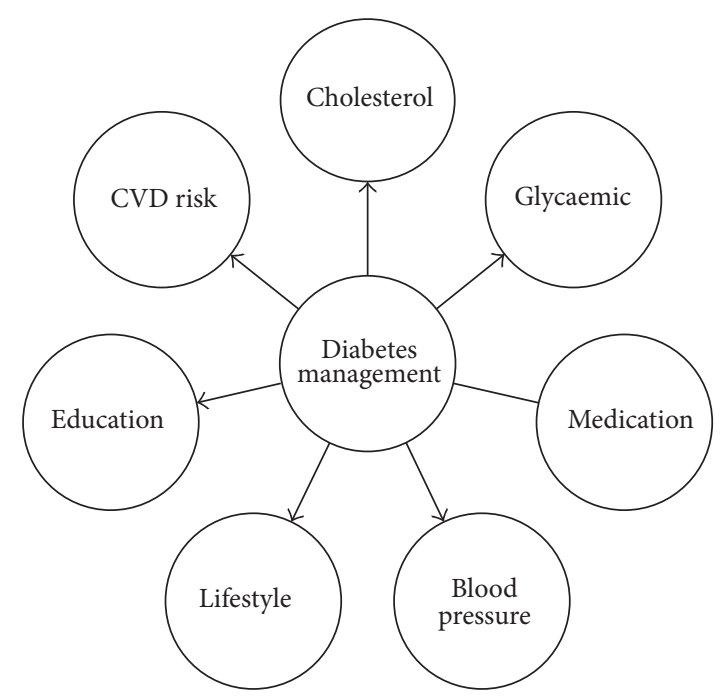

FIGURE 1: Summary of the seven evidence-based factors required in diabetes management.

and stress reduction contribute to achievement of glycaemic control $[41,42]$. Intensive lifestyle interventions resulted in reduction of more than 5\% weight loss and the loss was maintained at the fourth year in the Look AHEAD (Action for Health in Diabetes) study [43]. However, there is lack of intervention studies on other lifestyle issues such as foot care despite neuropathy being a major diabetes related complication. In 2005, there were about 10,000 hospital admissions for diabetes related foot ulcers in Australia resulting in lower limb amputations [44]. In the USA, the annual cost of diabetes foot ulcers is USD9-13 billion in addition to other diabetes costs [45].

(6) Education. A Malaysian study showed that one of the barriers to achieving good glycaemic control includes lack of understanding and knowledge of diabetes [46]. Educating diabetes patients on the management of their disease can significantly improve glycaemic [47-50], BP [49] and cholesterol control [48, 51], physical activity [49-51], dietary management [51], and medication understanding and adherence $[49,50]$.

(7) CVD Risk Prevention Strategies. Guidelines from Europe, the UK, and USA suggest aspirin therapy ( $75 \mathrm{mg}-162 \mathrm{mg} /$ day) as primary preventative strategy for increased CVD risk (10 year risk $>10 \%)[24,52,53]$. Cardiovascular disease risk can be estimated using risk prediction formulae such as the Framingham Risk Score and the UKPDS tool for diabetics. In Australia, the absolute CVD disease risk chart/calculator was developed using the Framingham risk equation [54]. USA guidelines recommend the use of the Framingham risk score. The Framingham risk score calculates percentage of CVD risk in 10 years using a patient's information on age, family history of CVD, gender, total cholesterol level, HDL cholesterol level, whether he/she is a smoker, has diabetes, or has systolic BP level, and whether the patient is treated for high blood pressure [55].
3.2. Practice Guidelines and Multifactorial Intervention Studies. Diabetes practice guidelines aim to achieve a range of outcomes such as the reduction of microvascular and macrovascular complications, improvement in quality of life (QOL), and prevention of premature mortality. Reductions in several diabetes complications such as kidney failure and amputation were observed as more patients received guideline-adherent therapy [56]. However, there is evidence that guidelines are not always being followed in clinical practice. In a recent cross-sectional study, it was found that among 650 Malaysian outpatients, $32.1 \%$ of diabetes patients with hypertension were not on an antihypertensive such as an ACEI or ARB as per guideline recommendations, although these patients had no contraindications to these antihypertensives [57]. A similar study conducted among 430 Australian diabetes patients found evidence-based practice gaps especially in the prescribing of antihypertensive and lipid lowering medications [58].

The multifactorial interventions described in diabetes studies often do not encompass all seven factors addressed in the diabetes guidelines. Diabetes intervention studies led by healthcare professionals other than pharmacists indicated improvements in patients' outcomes. However, there are inconsistencies in terms of the number of diabetes factors being addressed. While some studies emphasised selfmanagement [59-62], others focused only on diet [41] or adherence [63]. Some studies evaluated motivational interviewing to promote behavioural changes and belief among diabetes patients which resulted in improved glycaemic control, adherence, and lifestyle changes [64-69]. Interventions which focused on four factors, namely, nutrition, blood glucose monitoring, medication taking, and lifestyle improved HbAlc and health related QOL [12, 70, 71]. These studies are summarised in Table 2. However, data on the number of patients seeking emergency treatment or who had adverse events in comparison to the usual care group were not always mentioned. Adverse events such as hypoglycemia are not 
uncommon among diabetes patients, as reported in a metaanalysis and prospective study carried out in seven countries $[35,72]$.

3.3. Pharmacist Led Medication Management Services. The CPGs on diabetes from Australia, Europe, the UK, and USA suggest multiprofessional teamwork when managing patients $[24,25,52,53,73]$. One such approach is pharmacist led medication management services (MMS). MMS involves pharmacists working in collaboration with other healthcare professionals such as doctors or endocrinologists, diabetes nurses, and dietitians to improve patient outcomes and health related QOL which could reduce visits to general practitioners (GPs) and hospitalisation rates [74]. MMS pharmacists assess patients' medication to identify, resolve, and prevent medication-related problems. A care plan with recommendations to the physician or practitioner is developed to optimize medication and achieve goals of therapy. Patients are then followed up by the MMS pharmacist to monitor outcomes. MMS studies carried out in different parts of the world suggest that pharmacists in collaboration with other healthcare professionals can make significant improvements in therapy outcomes. Previous studies have reported improvement in HbAlc levels [47, 75-80], reduction in CVD risk score $[77,81]$, reduction in cholesterol levels [82, 83], and improvement in lifestyle factors [75, 83, 84]. These studies are grouped and summarised according to similar intervention strategies in Table 3.

These studies managed to reduce $\mathrm{HbAlc}$ between $0.6 \%$ and $1.8 \%$. In accordance with the ACCORD trial it was demonstrated that each $1 \%$ reduction in $\mathrm{HbAlc}$ reduced $21 \%$ of diabetes related endpoints such as macrovascular complications, $21 \%$ of deaths associated with diabetes, $14 \%$ risk of myocardial infarction, and $37 \%$ of microvascular complications [94].

In addition, several studies incorporating QOL on seven attributes, namely, vision, hearing, speech, ambulation, dexterity, emotion, and cognition, reported positive results $[76,80,92]$. QOL measurement is widely accepted as an important goal in health interventions [32] and these studies provide evidence for pharmacists' value in improving both clinical and QOL outcomes for diabetes patients.

3.4. Limitations in Medication Management Services. Findings from the Cochrane Collaboration suggested that pharmacist-provided patient oriented services may improve glycaemic control, BP, cholesterol, and QOL of diabetes patients, suggesting that pharmacists' services may reduce visits to GPs and hospitals [74]. Despite this, a 2014 National Centre for Health Statistics report from the USA Department of Health and Human Services found an increase in GP visits made by diabetes patients [95]. The report, however, did not stipulate the reasons for these increases. Several issues could have contributed such as failure to address all seven factors in diabetes management, lack of patient contact with pharmacists, pharmacists' restricted access to patient medical notes, pharmacists' lack of experience in medication management, increasing workload for pharmacists, and sustainability of methods used in medication management services.
Pharmacist RCTs on medication management services do not provide evidence of the seven diabetes management factors that should be addressed in diabetes care as these factors were not consistently incorporated in patient interactions. Despite some studies showing more than $1 \%$ reduction of HbAlc, other studies which used the same intervention method showed less reduction or in some cases no difference. The range of $\mathrm{HbAlc}$ reduction in $\mathrm{RCTs}$ which focused on three or less of the seven factors were $0.8 \%$ to $1.0 \%[78,83,85$, 90] while RCTs which incorporated four to five factors produced a reduction of $0.6 \%$ to $1.7 \%$ [47, $75,80,82,84,86]$. In studies which incorporated six to seven evidence-based factors, the HbAlc range improved by $0.5 \%$ to $1.8 \%[77,79,91]$.

It is uncertain if other variables are responsible for these outcomes, for instance, frequent face-to-face contact with patients. RCTs mentioned in Table 3 included frequent visits to the pharmacy every two to four weeks. These studies reported a HbAlc reduction which ranged between $0.5 \%$ and $1.7 \%$. However these intervention groups may have had positive outcomes due to the regular contact with the pharmacist and not due to the nature of the intervention itself, as suggested by several studies [96, 97]. Therefore, patients who show less commitment to intervention programs may obtain less benefit. In addition, it is uncertain whether positive clinical outcomes continue after patients' face-to-face management ends.

The methods used to assess the patients' adherence towards medications were not clearly defined in some studies [78, 80, 82, 91] while other studies used varied assessment methods [79, 85-87]. These unstandardised methods could have contributed to the difference in patient outcomes. The assessment methods mentioned in these RCTs were the ASK20 (Adherence starts with knowledge), prescription refill rates and self report, eight-item modified Morisky adherence assessment score, and the four-item Morisky adherence assessment score.

Lack of access to patients' medical notes and laboratory data may be a barrier for community pharmacists to provide quality medication management compared to pharmacists in hospital settings. In a study conducted in a GP clinic in Australia where pharmacists had access to patient's medical data the results showed increased medication adherence and improved patient satisfaction [98]. The importance of electronic health records in improving healthcare delivery has prompted the USA government to pass legislation to better integrate information technology into healthcare delivery in 2009 [99]. This enabled community pharmacists providing medication management services in the USA to access patients' medical records including information about medications, laboratory, and radiology results. Nevertheless, access to patients' medical notes remains limited to most community pharmacists in the USA [100]. In the UK, pharmacists were only given access to patients' summary care records in 2015 [101].

The majority of the interventions in the clinical trials were conducted by pharmacists with a minimum of three years of experience [75-82,87]. Thus, there are uncertainties as to whether pharmacists with limited experience can produce similar clinical outcomes in practice settings. Another issue 


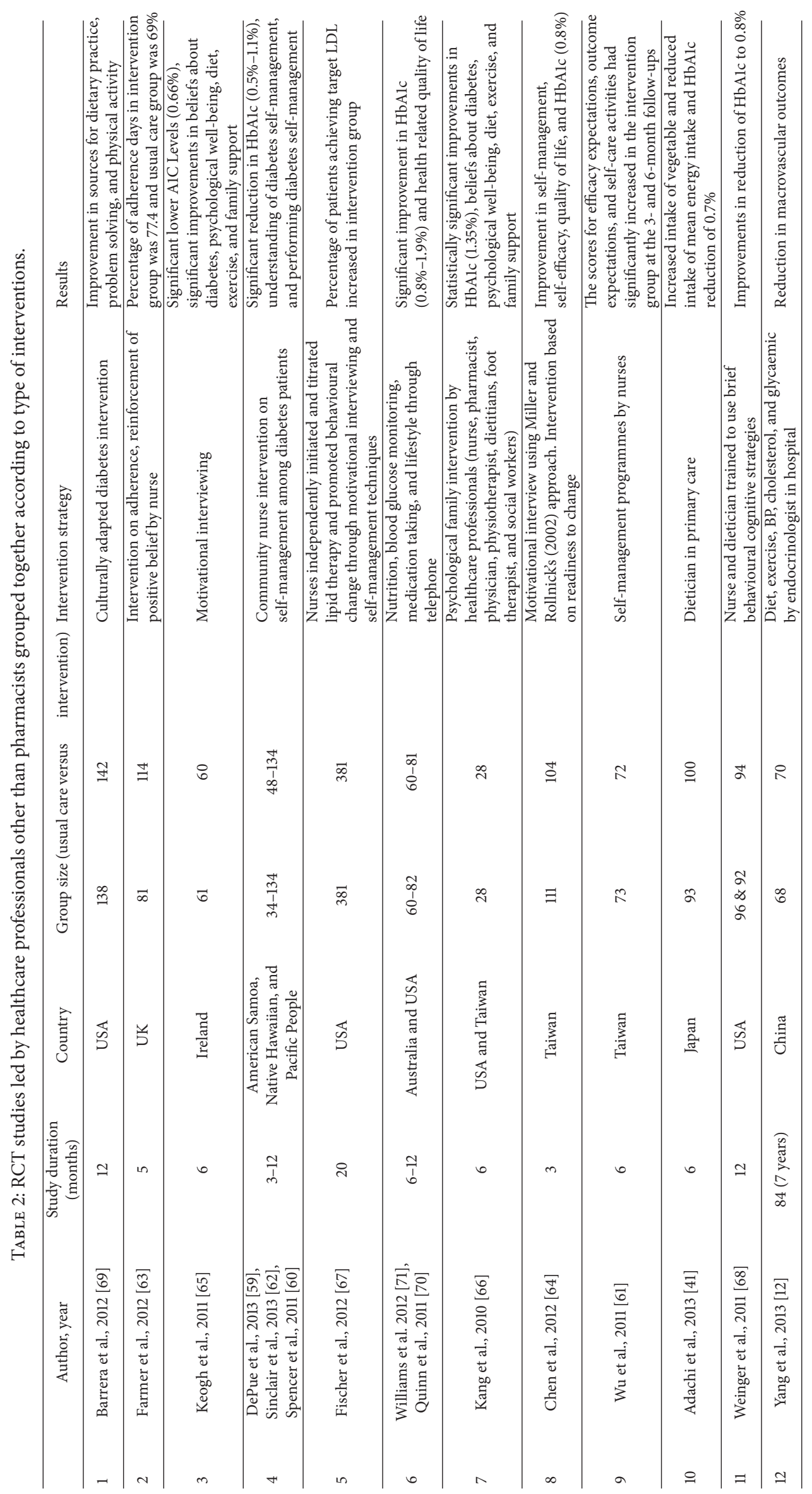




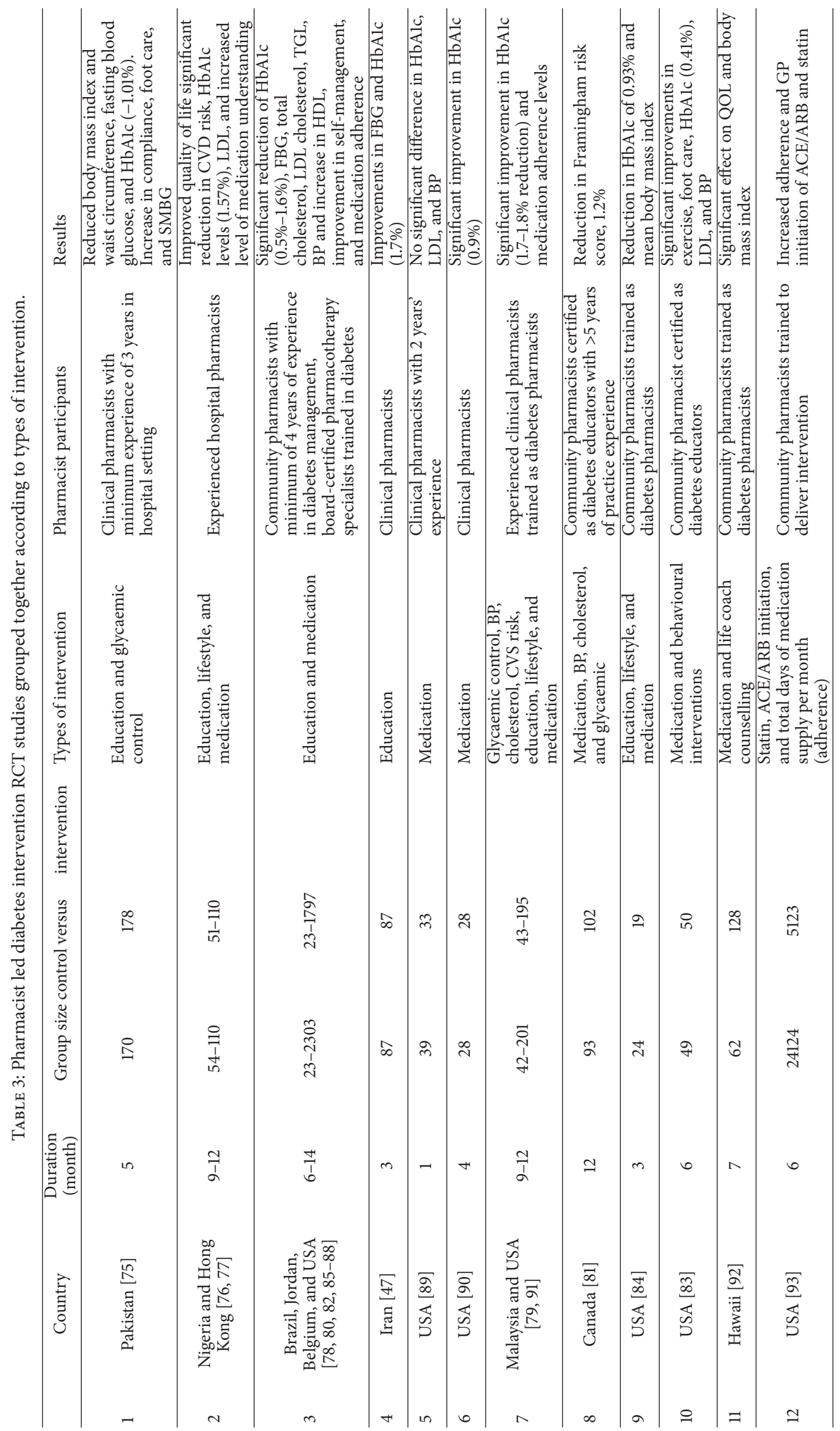


to consider is that although medication management services are accepted and being practised in many countries, pharmacists are still burdened with dispensing workloads, inadequate staff, and lack of time in carrying out services [102-104].

3.5. Long Term Outcomes. The duration of most diabetes intervention studies ranges between three to 14 months. The improvement in clinical outcomes could therefore only be evaluated over a short-term period. As the main goal in diabetes management is prevention of diabetes related complications such as nephropathy and CVD, there is a need for a long term study incorporating multifactorial interventions. One RCT study of 150 patients followed up for seven years in China [12] found that diabetes nephropathy can be delayed and macrovascular disease can be prevented using tightly controlled BP, cholesterol, and glycaemic targets as defined in USA guidelines. However this study was carried out in a hospital rather than a community setting. As such it remains uncertain if these methods can be translated into primary healthcare settings.

\subsection{Opportunities for Pharmacists in Preventing Diabetes} Complications. In comparison to other healthcare professionals involved in diabetes care, pharmacists are better qualified in pharmacology of medicines and assessment of medication-related problems. In contrast to GPs, community pharmacists are easily accessible to the public with extended opening hours and without the need for prior appointments. They are therefore able to provide medication review services to most people with diabetes. Undoubtedly, pharmacists play an important role and therefore should take on a bigger role in providing diabetes care and further ease the burden off general practitioners.

In order to support pharmacists in delivering consistent quality diabetes care that addresses all the seven evidencebased factors, a structured intervention method may be beneficial. This could take the form of a tool with support materials, checklists, or structured interview questions. Currently there are no published studies on the effectiveness of a standardised and structured method for pharmacists delivering diabetes management.

\section{Conclusion}

This narrative review has highlighted the seven evidencebased factors involved to prevent or delay diabetes related complications and achieve target therapy outcomes. While our findings identified a lack of consistent and systematic multifactorial evidence-based approaches in delivering diabetes care, it did demonstrate pharmacists' contributions towards improving clinical and QOL outcomes. This review has revealed some questions in need of further investigations, in particular, the impact of pharmacists' interventions on all seven evidence-based factors and the effect of long term clinical and health related QOL outcomes.

\section{Competing Interests}

The authors declare that they have no competing interests.

\section{References}

[1] World Health Organization (WHO), Global Health Estimates: Deaths by Cause, Age, Sex and Country, 2000-2012, World Health Organization (WHO), Geneva, Switzerland, 2014.

[2] N. J. Morrish, S.-L. Wang, L. K. Stevens et al., "Mortality and causes of death in the WHO multinational study of vascular disease in diabetes," Diabetologia, vol. 44, supplement 2, pp. S14-S21, 2001.

[3] World Health Organization (WHO), Global Status Report on Noncommunicable Diseases 2010, World Health Organization (WHO), Geneva, Switzerland, 2011.

[4] WHO, Global Data on Visual Impairments 2010, World Health Organization, Geneva, Switzerland, 2012.

[5] P. Zhang, X. Zhang, J. Brown et al., "Global healthcare expenditure on diabetes for 2010 and 2030," Diabetes Research and Clinical Practice, vol. 87, no. 3, pp. 293-301, 2010.

[6] Ministry of Health, Management of Type 2 Diabetes Mellitus, Ministry of Health, Putrajaya, Malaysia, 2009.

[7] S. J. Griffin, K. Borch-Johnsen, M. J. Davies et al., "Effect of early intensive multifactorial therapy on 5-year cardiovascular outcomes in individuals with type 2 diabetes detected by screening (ADDITION-Europe): a cluster-randomised trial," The Lancet, vol. 378, no. 9786, pp. 156-167, 2011.

[8] O. Vaccaro, L. Franzini, R. Miccoli et al., "Feasibility and effectiveness in clinical practice of a multifactorial intervention for the reduction of cardiovascular risk in patients with type 2 diabetes: the 2-year interim analysis of the MIND.IT study: a cluster randomized trial," Diabetes Care, vol. 36, no. 9, pp. 25662572, 2013.

[9] P. S. Koekkoek, C. Ruis, M. Van Den Donk et al., "Intensive multifactorial treatment and cognitive functioning in screendetected type 2 diabetes-the ADDITION-Netherlands study: a cluster-randomized trial," Journal of the Neurological Sciences, vol. 314, no. 1-2, pp. 71-77, 2012.

[10] J. M. Gamble, H. Holly, D. T. Eurich, K. K. Jindal, and P. A. Senior, "Patient-level evaluation of community-based, multifactorial intervention to prevent diabetic nephropathy in Northern Alberta, Canada," Journal of Primary Care \& Community Health, vol. 3, no. 2, pp. 111-119, 2012.

[11] S.-T. Tu, S.-J. Chang, J.-F. Chen et al., "Prevention of diabetic nephropathy by tight target control in an Asian population with type 2 diabetes mellitus: a 4-year prospective analysis," Archives of Internal Medicine, vol. 170, no. 2, pp. 155-161, 2010.

[12] Y. Yang, J.-J. Yao, J.-L. Du et al., "Primary prevention of macroangiopathy in patients with short-duration type 2 diabetes by intensified multifactorial intervention: seven-year follow-up of diabetes complications in Chinese," Diabetes Care, vol. 36, no. 4, pp. 978-984, 2013.

[13] S. D. Prato, J. LaSalle, S. Matthaei, and C. J. Bailey, “Tailoring treatment to the individual in type 2 diabetes practical guidance from the Global Partnership for Effective Diabetes Management," International Journal of Clinical Practice, vol. 64, no. 3, pp. 295-304, 2010.

[14] P. King, I. Peacock, and R. Donnelly, “The UK Prospective Diabetes Study (UKPDS): clinical and therapeutic implications for type 2 diabetes," British Journal of Clinical Pharmacology, vol. 48, no. 5, pp. 643-648, 1999.

[15] S. R. Heller, "A summary of the ADVANCE trial," Diabetes Care, vol. 32, supplement 2, pp. S357-S361, 2009. 
[16] W. Duckworth, C. Abraira, T. Moritz et al., "Glucose control and vascular complications in veterans with type 2 diabetes," New England Journal of Medicine, vol. 360, no. 2, pp. 129-139, 2009.

[17] G. Worrall, "Results of the DCCT trial. Implications for managing our patient with diabetes," Canadian Family Physician, vol. 40, pp. 1955-1963, 1994.

[18] J. B. Buse, "Action to control cardiovascular risk in diabetes (ACCORD) trial: design and methods," The American Journal of Cardiology, vol. 99, no. 12, supplement, pp. S21-S33, 2007.

[19] D. M. Nathan, H. Turgeon, and S. Regan, "Relationship between glycated haemoglobin levels and mean glucose levels over time," Diabetologia, vol. 50, no. 11, pp. 2239-2244, 2007.

[20] H. Rodbard, P. Jellinger, J. Davidson et al., "Statement by an American Association of Clinical Endocrinologists/American College of Endocrinology consensus panel on type 2 diabetes mellitus: an algorithm for glycemic control," Endocrine Practice, vol. 15, no. 6, pp. 540-559, 2009.

[21] L. C. Hay, E. G. Wilmshurst, and G. Fulcher, "Unrecognized hypo- and hyperglycemia in well-controlled patients with type 2 diabetes mellitus: the results of continuous glucose monitoring," Diabetes Technology and Therapeutics, vol. 5, no. 1, pp. 19-26, 2003.

[22] J. P. Jansen, "Self-monitoring of glucose in type 2 diabetes mellitus: a Bayesian meta-analysis of direct and indirect comparisons," Current Medical Research and Opinion, vol. 22, no. 4, pp. 671-681, 2006.

[23] D. C. Klonoff, R. M. Bergenstal, L. Blonde et al., "Consensus report of the coalition for clinical research-self-monitoring of blood glucose," Journal of Diabetes Science and Technology, vol. 2, no. 6, pp. 1030-1053, 2008.

[24] American Association of Clinical Endocrinologists and American College of Endocrinology, "Clinical practice guidelines for developing a diabetes mellitus comprehensive care plan," Endocrine Practice, vol. 21, no. 1, pp. 1-87, 2015.

[25] Diabetes Management in General Practice, Australian Guidelines for Type 2 Diabetes, 2014-2015.

[26] American Diabetes Association, "Standards of medical care in diabetes," Diabetes Care, vol. 37, pp. 1-67, 2015.

[27] N. Sattar, D. Preiss, H. M. Murray et al., "Statins and risk of incident diabetes: a collaborative meta-analysis of randomised statin trials," The Lancet, vol. 375, no. 9716, pp. 735-742, 2010.

[28] S. M. Liew, P. Y. Lee, N. S. Hanafi et al., "Statins use is associated with poorer glycaemic control in a cohort of hypertensive patients with diabetes and without diabetes, Diabetology \& Metabolic Syndrome, vol. 6, article 53, 5 pages, 2014.

[29] P. M. Ridker, A. Pradhan, J. G. MacFadyen, P. Libby, and R. J. Glynn, "Cardiovascular benefits and diabetes risks of statin therapy in primary prevention: an analysis from the JUPITER trial," The Lancet, vol. 380, no. 9841, pp. 565-571, 2012.

[30] S. N. Rajpathak, D. J. Kumbhani, J. Crandall, N. Barzilai, M. Alderman, and P. M. Ridker, "Statin therapy and risk of developing type 2 diabetes: a meta-analysis," Diabetes Care, vol. 32, no. 10, pp. 1924-1929, 2009.

[31] U.S. Food and Drug Administration, FDA Drug Safety Communication: Important Safety Label Changes to CholesterolLowering Statin Drugs, 2012, http://www.fda.gov/Drugs/DrugSafety/ucm293101.htm.

[32] C. D. Hepler and L. M. Strand, "Opportunities and responsibilities in pharmaceutical care," American Journal of Hospital Pharmacy, vol. 47, no. 3, pp. 533-543, 1990.
[33] L. M. Strand, R. J. Cipolle, and M. J. Frakes, Medication Adherence: Improved Results with Comprehensive Medication Therapy Management Services, Medication Management Systems, 2007.

[34] V. Ruelas, G. M. Roybal, Y. Lu, D. Goldman, and A. Peters, "Clinical and behavioral correlates of achieving and maintaining glycemic targets in an underserved population with type 2 diabetes," Diabetes Care, vol. 32, no. 1, pp. 54-56, 2009.

[35] F. Á. Guisasola, S. T. Povedano, G. Krishnarajah, R. Lyu, P. Mavros, and D. Yin, "Hypoglycaemic symptoms, treatment satisfaction, adherence and their associations with glycaemic goal in patients with type 2 diabetes mellitus: findings from the RealLife Effectiveness and Care Patterns of Diabetes Management (RECAP-DM) Study," Diabetes, Obesity and Metabolism, vol. 10, no. 1, pp. 25-32, 2008.

[36] A. K. Jha, R. E. Aubert, J. Yao, J. R. Teagarden, and R. S. Epstein, "Greater adherence to diabetes drugs is linked to less hospital use and could save nearly $\$ 5$ billion annually," Health Affairs, vol. 31, no. 8, pp. 1836-1846, 2012.

[37] W. C. Lee, S. Balu, D. Cobden, A. V. Joshi, and C. L. Pashos, "Prevalence and economic consequences of medication adherence in diabetes: a systematic literature review," Managed Care Interface, vol. 19, no. 7, pp. 31-41, 2006.

[38] L. Breitscheidel, S. Stamenitis, F.-W. Dippel, and O. Schöffski, "Economic impact of compliance to treatment with antidiabetes medication in type 2 diabetes mellitus: a review paper," Journal of Medical Economics, vol. 13, no. 1, pp. 8-15, 2010.

[39] K. L. Hepke, M. T. Martus, and D. A. Share, "Costs and utilization associated with pharmaceutical adherence in a diabetic population," The American Journal of Managed Care, vol. 10, no. 2, pp. 144-151, 2004.

[40] M. C. Sokol, K. A. McGuigan, R. R. Verbrugge, and R. S. Epstein, "Impact of medication adherence on hospitalization risk and healthcare cost," Medical Care, vol. 43, no. 6, pp. 521-530, 2005.

[41] M. Adachi, K. Yamaoka, M. Watanabe et al., "Effects of lifestyle education program for type 2 diabetes patients in clinics: a cluster randomized controlled trial," BMC Public Health, vol. 13, article 467, 2013.

[42] R. H. Bishay, A. Omari, J. Zang et al., "Divide and conquer: the multidisciplinary approach to achieving significant long-term weight loss and improved glycemic control in obese patients with type 2 diabetes," Clinical Diabetes, vol. 31, no. 1, pp. 14-20, 2013.

[43] T. A. Wadden, R. H. Neiberg, R. R. Wing et al., "Four-year weight losses in the look AHEAD study: factors associated with long-term success," Obesity, vol. 19, no. 10, pp. 1987-1998, 2011.

[44] Australian Institute of Health and Welfare, Diabetes: Australian Facts, Australian Institute of Health and Welfare, Canberra, Australia, 2008.

[45] J. B. Rice, U. Desai, A. K. G. Cummings, H. G. Birnbaum, M. Skornicki, and N. B. Parsons, "Burden of diabetic foot ulcers for medicare and private insurers," Diabetes Care, vol. 37, no. 3, pp. 651-658, 2014.

[46] S. M. Ali, "Barriers to optimal control of type 2 diabetes in Malaysian Malay patients," Global Journal of Health Science, vol. 1, no. 2, pp. 106-118, 2009.

[47] S. Farsaei, A. M. Sabzghabaee, A. H. Zargarzadeh, and M. Amini, "Effect of pharmacist-led patient education on glycemic control of type 2 diabetics: a randomized controlled trial," Journal of Research in Medical Sciences, vol. 16, no. 1, pp. 43-49, 2011. 
[48] A. Philis-Tsimikas, A. Fortmann, L. Lleva-Ocana et al., "Peerled diabetes education programs in high-risk Mexican Americans improve glycemic control compared with standard approaches: a Project Dulce promotora randomized trial," Diabetes Care, vol. 34, no. 9, pp. 1926-1931, 2011.

[49] E. Beyazit and M. Mollaoğlu, "Investigation of effect on glycosylated hemoglobin, blood pressure, and body mass index of diabetes intensive education program in patients with Type 2 diabetes mellitus," American Journal of Men's Health, vol. 5, no. 4, pp. 351-357, 2011.

[50] M. Y. Tan, J. M. Magarey, S. S. Chee, L. F. Lee, and M. H. Tan, "A brief structured education programme enhances self-care practices and improves glycaemic control in Malaysians with poorly controlled diabetes," Health Education Research, vol. 26, no. 5, pp. 896-907, 2011.

[51] M. Moriyama, M. Nakano, Y. Kuroe, K. Nin, M. Niitani, and T. Nakaya, "Efficacy of a self-management education program for people with type 2 diabetes: results of a 12 month trial," Japan Journal of Nursing Science, vol. 6, no. 1, pp. 51-63, 2009.

[52] International Diabetes Federation, Global Guideline for Type 2 Diabetes, vol. 2, International Diabetes Federation, Brussels, Belgium, 2012.

[53] National Institute for Health and Care Excellence (NICE), The Management of Type 2 Diabetes, National Institute for Health and Care Excellence (NICE), London, UK, 2014.

[54] National Vascular Disease Prevention Alliance, Guidelines for the Management of Absolute Cardiovascular Disease Risk, NVDPA, 2012.

[55] R. B. D’Agostino Sr., R. S. Vasan, M. J. Pencina et al., “General cardiovascular risk profile for use in primary care: the Framingham Heart study," 2008, http://www.framinghamheartstudy .org/risk-functions/cardiovascular-disease/10-year-risk.php\#.

[56] P. J. O'Connor, N. L. Bodkin, J. Fradkin et al., "Diabetes performance measures: current status and future directions," Diabetes Care, vol. 34, no. 7, pp. 1651-1659, 2011.

[57] N. Ahmad, Y. Hassan, B. Tangiisuran et al., "Guidelines adherence and hypertension control at a tertiary hospital in Malaysia," Journal of Evaluation in Clinical Practice, vol. 19, no. 5, pp. 798804, 2013.

[58] I. Krass, R. Hebing, B. Mitchell et al., "Diabetes management in an Australian primary care population," Journal of Clinical Pharmacy and Therapeutics, vol. 36, no. 6, pp. 664-672, 2011.

[59] J. D. DePue, S. Dunsiger, A. D. Seiden et al., "Nurse-community health worker team improves diabetes care in American Samoa: results of a randomized controlled trial," Diabetes Care, vol. 36, no. 7, pp. 1947-1953, 2013.

[60] M. S. Spencer, A.-M. Rosland, E. C. Kieffer et al., "Effectiveness of a community health worker intervention among African American and Latino adults with type 2 diabetes: a randomized controlled trial," American Journal of Public Health, vol. 101, no. 12, pp. 2253-2260, 2011.

[61] S.-F. V. Wu, M.-C. Lee, S.-Y. Liang, Y.-Y. Lu, T.-J. Wang, and H.H. Tung, "Effectiveness of a self-efficacy program for persons with diabetes: a randomized controlled trial," Nursing and Health Sciences, vol. 13, no. 3, pp. 335-343, 2011.

[62] K. A. Sinclair, E. K. Makahi, C. Shea-Solatorio, S. R. Yoshimura, C. K. M. Townsend, and J. K. Kaholokula, "Outcomes from a diabetes self-management intervention for native hawaiians and pacific people: partners in care," Annals of Behavioral Medicine, vol. 45, no. 1, pp. 24-32, 2013.

[63] A. Farmer, W. Hardeman, D. Hughes et al., "An explanatory randomised controlled trial of a nurse-led, consultation-based intervention to support patients with adherence to taking glucose lowering medication for type 2 diabetes," BMC Family Practice, vol. 13, article 30, 2012.

[64] S. M. Chen, D. Creedy, H.-S. Lin, and J. Wollin, "Effects of motivational interviewing intervention on self-management, psychological and glycemic outcomes in type 2 diabetes: a randomized controlled trial," International Journal of Nursing Studies, vol. 49, no. 6, pp. 637-644, 2012.

[65] K. M. P. Keogh, S. M. M. D. Smith, P. White et al., "Psychological family intervention for poorly controlled type 2 diabetes," The American Journal of Managed Care, vol. 17, no. 2, pp. 105-113, 2011.

[66] C.-M. Kang, S.-C. Chang, P.-L. Chen et al., "Comparison of family partnership intervention care vs. conventional care in adult patients with poorly controlled type 2 diabetes in a community hospital: a randomized controlled trial," International Journal of Nursing Studies, vol. 47, no. 11, pp. 1363-1373, 2010.

[67] H. H. Fischer, S. L. Eisert, R. M. Everhart et al., "Nurse-run, telephone-based outreach to improve lipids in people with diabetes," The American Journal of Managed Care, vol. 18, no. 2, pp. 77-84, 2012.

[68] K. Weinger, E. A. Beverly, Y. Lee, L. Sitnokov, O. P. Ganda, and A. E. Caballero, "The effect of a structured behavioral intervention on poorly controlled diabetes: a randomized controlled trial," Archives of Internal Medicine, vol. 171, no. 22, pp. 1990-1999, 2011.

[69] M. Barrera Jr., D. Toobert, L. Strycker, and D. Osuna, "Effects of acculturation on a culturally adapted diabetes intervention for latinas," Health Psychology, vol. 31, no. 1, pp. 51-54, 2012.

[70] C. C. Quinn, M. D. Shardell, M. L. Terrin, E. A. Barr, S. H. Ballew, and A. L. Gruber-Baldini, "Cluster-randomized trial of a mobile phone personalized behavioral intervention for blood glucose control," Diabetes Care, vol. 34, no. 9, pp. 1934-1942, 2011.

[71] E. D. Williams, D. Bird, A. W. Forbes et al., "Randomised controlled trial of an automated, interactive telephone intervention (TLC Diabetes) to improve type 2 diabetes management: baseline findings and six-month outcomes," BMC Public Health, vol. 12, no. 1, article 602, 2012.

[72] J. Belsey and G. Krishnarajah, "Glycaemic control and adverse events in patients with type 2 diabetes treated with metformin + sulphonylurea: a meta-analysis," Diabetes, Obesity and Metabolism, vol. 10, supplement 1, pp. 1-7, 2008.

[73] S. E. Inzucchi, R. M. Bergenstal, J. B. Buse et al., "Management of hyperglycaemia in type 2 diabetes: a patient-centred approach. Position statement of the American Diabetes Association (ADA) and the European Association for the Study of Diabetes (EASD)," Diabetologia, vol. 35, no. 6, 2012.

[74] S. Pande, J. E. Hiller, N. Nkansah, and L. Bero, "The effect of pharmacist-provided non-dispensing services on patient outcomes, health service utilisation and costs in low- and middle-income countries," Cochrane Database of Systematic Reviews, no. 2, Article ID CD010398, pp. 1-71, 2013.

[75] A. M. Samtia, M. F. Rasool, N. M. Ranjha, F. Usman, and I. Javed, "A multifactorial intervention to enhance adherence to medications and disease-related knowledge in type 2 diabetic patients in Southern Punjab, Pakistan," Tropical Journal of Pharmaceutical Research, vol. 12, no. 5, pp. 851-856, 2013.

[76] M. O. Adibe, C. V. Ukwe, and C. N. Aguwa, "The impact of pharmaceutical care intervention on the quality of life of nigerian patients receiving treatment for type 2 diabetes," Value in Health Regional Issues, vol. 2, no. 2, pp. 240-247, 2013. 
[77] C.-W. Chan, S.-C. Siu, C. K. W. Wong, and V. W. Y. Lee, "A pharmacist care program: positive impact on cardiac risk in patients with type 2 diabetes," Journal of Cardiovascular Pharmacology and Therapeutics, vol. 17, no. 1, pp. 57-64, 2012.

[78] J. P. Jameson and P. J. Baty, "Pharmacist Collaborative Management of poorly controlled diabetes mellitus: a randomized controlled trial," The American Journal of Managed Care, vol. 16, no. 4, pp. 250-255, 2010.

[79] L. Navin Kumar, S. T. Chin, T. Rachet, K. Y. Lim, and A. Fudziah, "Clinical and economic impact of pharmacist-run medication therapy adherence clinic service on patients with type 2 diabetes," Malaysian Journal of Public Health Medicine, vol. 5, no. 11, p. 42, 2011.

[80] M. Ali, F. Schifano, P. Robinson et al., "Impact of community pharmacy diabetes monitoring and education programme on diabetes management: a randomized controlled study," Diabetic Medicine, vol. 29, no. 9, pp. e326-e333, 2012.

[81] N. N. Ladhani, S. R. Majumdar, J. A. Johnson et al., "Adding pharmacists to primary care teams reduces predicted long-term risk of cardiovascular events in Type 2 diabetic patients without established cardiovascular disease: results from a randomized trial," Diabetic Medicine, vol. 29, no. 11, pp. 1433-1439, 2012.

[82] A. O. M. Mourão, W. R. Ferreira, M. A. P. Martins et al., "Pharmaceutical care program for type 2 diabetes patients in Brazil: a randomised controlled trial," International Journal of Clinical Pharmacy, vol. 35, no. 1, pp. 79-86, 2013.

[83] L. B. Cohen, T. H. Taveira, S. A. M. Khatana, A. G. Dooley, P. A. Pirraglia, and W.-C. Wu, "Pharmacist-led shared medical appointments for multiple cardiovascular risk reduction in patients with type 2 diabetes," The Diabetes Educator, vol. 37, no. 6, pp. 801-812, 2011.

[84] A. M. Castejón, J. L. Calderón, A. Perez et al., "A communitybased pilot study of a diabetes pharmacist intervention in Latinos: impact on weight and hemoglobin Alc," Journal of Health Care for the Poor and Underserved, vol. 24, supplement 4, pp. 48-60, 2013.

[85] D. F. Kraemer, W. A. Kradjan, T. M. Bianco, and J. A. Low, "A randomized study to assess the impact of pharmacist counseling of employer-based health plan beneficiaries with diabetes: the EMPOWER study," Journal of Pharmacy Practice, vol. 25, no. 2, pp. 169-179, 2012.

[86] E. Mehuys, L. Van Bortel, L. De Bolle et al., "Effectiveness of a community pharmacist intervention in diabetes care: a randomized controlled trial," Journal of Clinical Pharmacy and Therapeutics, vol. 36, no. 5, pp. 602-613, 2011.

[87] A. S. Jarab, S. G. Alqudah, T. L. Mukattash, G. Shattat, and T. Al-Qirim, "Randomized controlled trial of clinical pharmacy management of patients with type 2 diabetes in an outpatient diabetes clinic in Jordan," Journal of Managed Care Pharmacy, vol. 18, no. 7, pp. 516-526, 2012.

[88] M. Heisler, T. P. Hofer, J. A. Schmittdiel et al., "Improving blood pressure control through a clinical pharmacist outreach program in patients with diabetes mellitus in 2 highperforming health systems: the adherence and intensification of medications cluster randomized, controlled pragmatic trial," Circulation, vol. 125, no. 23, pp. 2863-2872, 2012.

[89] J. L. Kirwin, R. J. Cunningham, and T. D. Sequist, "Pharmacist recommendations to improve the quality of diabetes care: a randomized controlled trial," Journal of Managed Care Pharmacy, vol. 16, no. 2, pp. 104-113, 2010.
[90] T. H. Taveira, P. D. Friedmann, L. B. Cohen et al., "Pharmacistled group medical appointment model in type 2 diabetes," Diabetes Educator, vol. 36, no. 1, pp. 109-117, 2010.

[91] M. Jacobs, P. S. Sherry, L. M. Taylor, M. Amato, G. R. Tataronis, and G. Cushing, "Pharmacist assisted medication program enhancing the regulation of diabetes (PAMPERED) study," Journal of the American Pharmacists Association, vol. 52, no. 5, pp. 613-621, 2012.

[92] C. Nishita, G. Cardazone, D. L. Uehara, and T. Tom, "Empowered diabetes management: life coaching and pharmacist counseling for employed adults with diabetes," Health Education and Behavior, vol. 40, no. 5, pp. 581-591, 2013.

[93] A. T. Brennan, J. T. Dollear, M. Hu et al., "An integrated pharmacy-based program improved medication prescription and adherence rates in diabetes patients," Health Affairs, vol. 31, no. 1, pp. 120-129, 2012.

[94] I. M. Stratton, A. I. Adler, H. A. W. Neil et al., "Association of glycaemia with macrovascular and microvascular complications of type 2 diabetes (UKPDS 35): prospective observational study," British Medical Journal, vol. 321, no. 7258, pp. 405-412, 2000.

[95] J. J. Ashman, A. Talwalkar, and S. A. Taylor, "Age differences in visits to office-based physicians by patients with diabetes: United States, 2010," in US Department of Health and Human Services, pp. 1-7, Centers for Disease Control and Prevention, Atlanta, Ga, USA, 2014.

[96] S. G. H. A. Swinnen and J. H. Devries, "Contact frequency determines outcome of basal insulin initiation trials in type 2 diabetes," Diabetologia, vol. 52, no. 11, pp. 2324-2327, 2009.

[97] D. S. Mshelia, O. M. Akinosun, and F. M. Abbiyesuku, "Effect of increased patient-physician contact time and health education in achieving diabetes mellitus management objectives in a resource-poor environment," Singapore Medical Journal, vol. 48, no. 1, pp. 74-79, 2007.

[98] E. C. K. Tan, K. Stewart, R. A. Elliott, and J. George, "Pharmacist consultations in general practice clinics: the Pharmacists in Practice Study (PIPS)," Research in Social and Administrative Pharmacy, vol. 10, no. 4, pp. 623-632, 2014.

[99] The impact of electronic health records on pharmacy practice. Drug topics.com, 2012, http://www.pharmacyhit.org/pdfs/ Article.pdf.

[100] F. Isasi and E. Krofah, The Expanding Role of Pharmacists in a Transformed Health Care System, National Governors Association Center for Best Practices, Washington, DC, USA, 2015.

[101] D. Andalo and E. Sukkar, "Risks and benefits of pharmacists accessing summary care records," The Pharmaceutical Journal, vol. 295, no. 7870, pp. 13-15, 2015.

[102] K. E. Herbert, J. M. Urmie, B. A. Newland, and K. B. Farris, "Prediction of pharmacist intention to provide Medicare medication therapy management services using the theory of planned behavior," Research in Social and Administrative Pharmacy, vol. 2, no. 3, pp. 299-314, 2006.

[103] L. R. Moczygemba, J. C. Barner, E. R. Gabrillo, and P. J. Godley, "Development and implementation of a telephone medication therapy management program for Medicare beneficiaries," American Journal of Health-System Pharmacy, vol. 65, no. 17, pp. 1655-1660, 2008.

[104] J. C. Schommer, L. G. Planas, K. A. Johnson, and W. R. Doucette, "Pharmacist-provided medication therapy management (part 2): payer perspectives in 2007," Journal of the American Pharmacists Association, vol. 48, no. 4, pp. 478-486, 2008. 


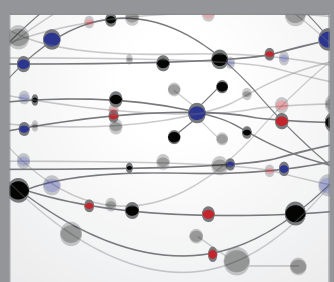

The Scientific World Journal
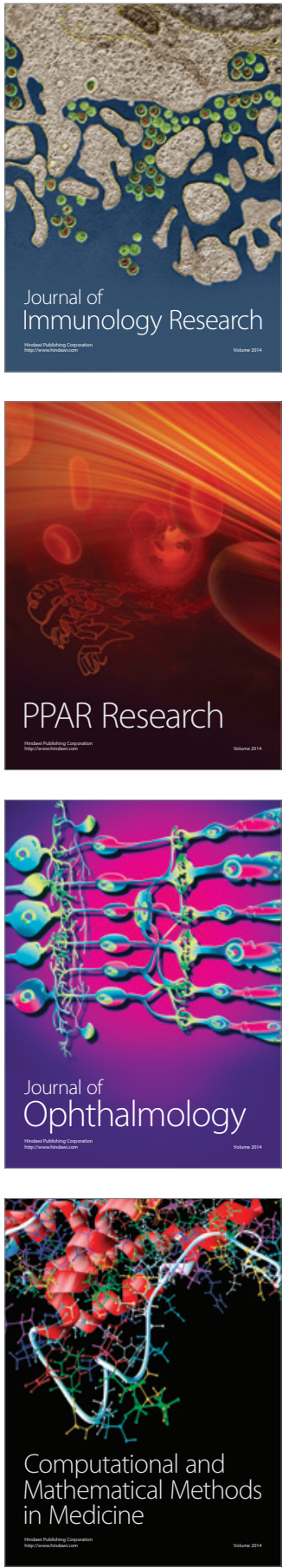

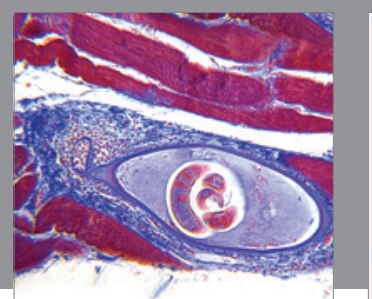

Gastroenterology Research and Practice

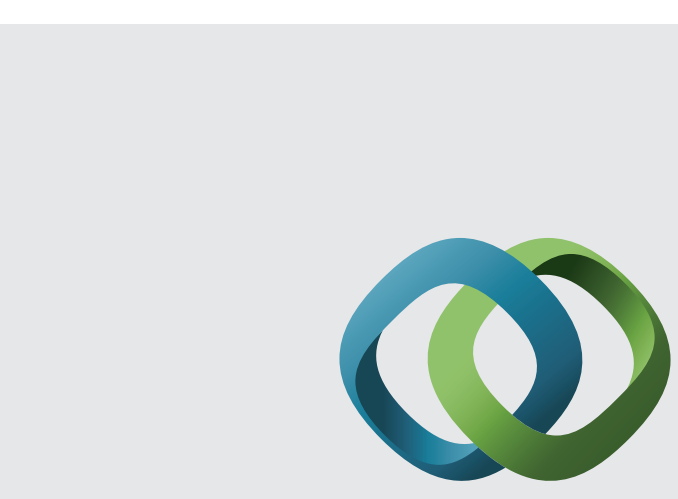

\section{Hindawi}

Submit your manuscripts at

http://www.hindawi.com
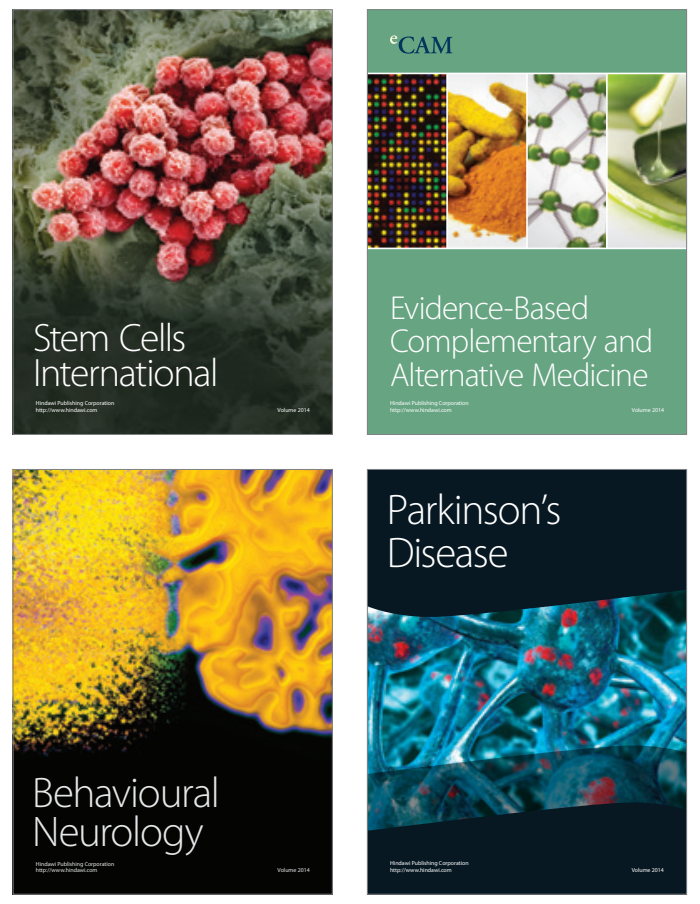
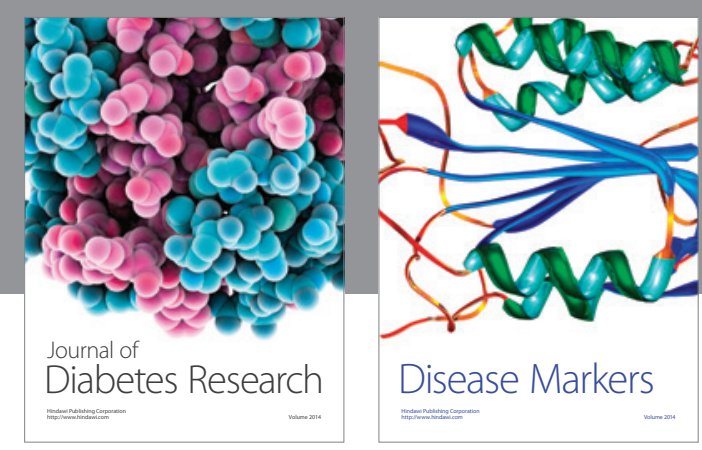

Disease Markers
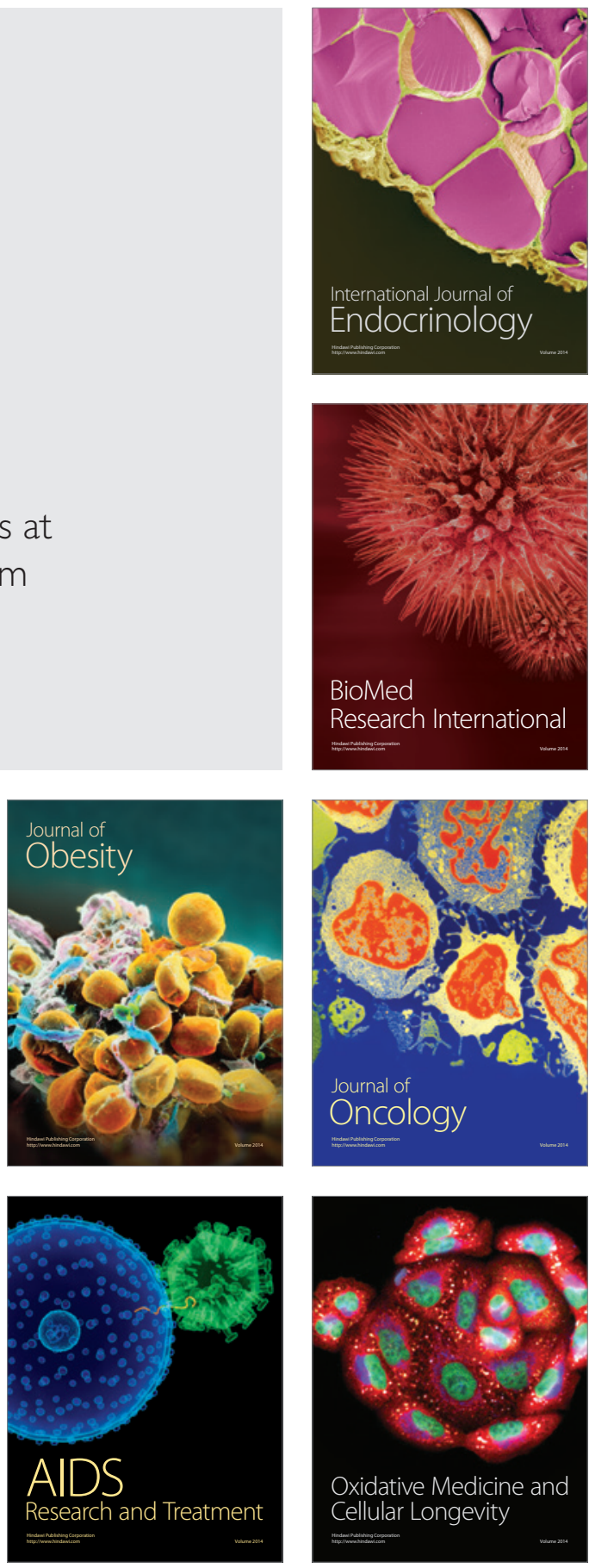